\title{
Urban Sprawl in Iranian Medium-sized Cities; Investigating the Role of Masterplans
}

\author{
Ali Soltani ${ }^{1}$, Mohammad Hosseinpour ${ }^{1} \&$ Ali Hajizadeh $^{1}$ \\ ${ }^{1}$ Department of Urban Planning, Shiraz University, Shiraz, Iran \\ Correspondence: Ali Soltani, Department of Urban Planning, Shiraz University, Shiraz, Iran. E-mail: \\ soltani@shirazu.ac.ir
}

Received: December 23, 2016

Accepted: January 3, 2017 Online Published: February 3, 2017

doi:10.5539/jsd.v10n1p122

URL: http://dx.doi.org/10.5539/jsd.v10n1p122

\begin{abstract}
Urban sprawl is one of the main important phenomena threatening the spatial structure of cities and affecting the overall quality of them. This paper studied the urban growth pattern and sprawling of Kazerun, a medium-sized city in the south of Iran. Using the population and land use data available from secondary formal sources, the growth pattern was compared to national statistics. Furthermore, two well-known landscape metrics included Holdern and Shannon indices were applied to measure the extent of urban sprawl. As a qualitative research methodology, some experts $(\mathrm{n}=30)$ working in governmental agencies were asked to explain the causes and effects of urban sprawl in the case study area. The results confirmed that several factors including the former masterplans affected the urban development pattern of the area. Moreover, a number of physical, environmental, economic and social impacts were discovered as the consequence of current fragmented growth pattern. Finally, a set of applicable policies are recommended to overcome sprawl and to achieve a more balanced development.
\end{abstract}

Keywords: urban growth, sprawl, medium-sized city, masterplan

\section{Introduction}

Urban sprawl is the spreading of developments and defined as low density commercial or residential development on vacant land which is unsustainable in a longer time (Squires, 2002). Urban sprawl is characterized by several impacts such as: low-density, dispersed, car dependent and environmentally and socially-segregated communities (Ewing, 1997; Downs, 1998; Burchell and Shad, 1999; Couch et al, 2007). Urban sprawl and its impacts have attracted increasing attention from planners and policy makers within the past three decades (Frenkel and Ashkenazi, 2008; Frenkel and Orenstein, 2012).

While large cities and metropolises are going toward more compression by applying policies to control sprawl, urban sprawl is also a risk that threatens the small and medium-sized cities (Ngoran and $\mathrm{Xu}$, 2015; Zeng et al., 2015; Yuen et al., 2013; García-Palomares , 2010; Davis and Schaub, 2005; Capello, and Camagni , 2000). In these types of cities, the role of urban masterplan is very effective and undeniable in terms of guiding urban development and preventing the urban sprawl (Kim and Rowe, 2013). Masterplans are expected to provide a context for coordinated and harmonious physical development. Actually, such plans encompass a set of decisions made by urban officials to create a more effective conformity between the city and the changes which are not under their control (Andersson and Samartin, 1983).

Several studies can be found discussing the role of masterplans in shaping the urban development pattern. For example, Tian and Shen (2011) and Han et al. (2009) evaluate the implementation impacts of masterplans of Guangzhou and Beijing, respectively, and found that the actual urban development pattern in both cities deviated greatly from the original master plans. Sharifi et al. (2014) studied the effectiveness of Laos's comprehensive plan in regulating urban growth. The results indicate that there was an urgent need for improvements in the regulatory and administrative aspects as the master plan should be revised to provide a more realistic account of the existing situation. The results of Kim and Row's (2013) study on the role of master plans to guide development toward areas with less risk in China's disaster-prone areas showed that cities showing high compliance with their master plans generally had smaller areas of urban land exposed to environmental hazards.

The early historical Iranian cities were organized into axial, geometrical patterns. The gated towns and villages that started to develop in eastern Iran from the middle of the first millennium BC were square-shaped and had an 
internal axial design. The main street was originated from a single gateway, was flanked by courtyard houses, and led to a central square, which was the public space for the cattle (Ahmadi et al., 2012). Organic cities as a product of hundreds of years of evolving are a valuable source for today's studies (Karimi, 2002). Today's massive sprawl is only a part of urban transformations that aimed at formulating the urban form of the cities for car use. These governmental practices that took place between 1930 and 1960 not only changed the urban textures of the traditional and organic cities, but also impacted the lifestyle of the urban residents by facilitating motorized movement (Masoumi, 2012).

Master planning in Iranian cities dates back to mid-1970s when the first wave of modernization appeared (Madanipour, 2006; Madanipour, 2010). However, this approach received many criticisms from the developed countries and was gradually replaced by other approaches such as systematic or strategic plan (Rasoolimanesh et al., 2013). Nevertheless, in Iran, the master plan is still considered as the dominant approach in planning. The master planning approach makes a rigid blueprint of the provincial level have high influence on the urban development with a minimum participation of management system (PanahandehKhah et al., 2009). The decision to provide and adopt a master plan in Iran is conducted via a joint work between Management and Planning Organization (MPO); the Urban Development Ministry, the Planning Department of Municipality, city council and provincial offices. In order to prepare such a master plan, urban planner and architecture experts are engaged in this process. These professionals aim to analyze the city's conditions and determine the priorities based on municipality and central government expectations (Mohammadi, 2010). Hence, there is clearly a lack of participation of citizens, non-governmental organizations (NGOs) and other stakeholders in the process of planning in the conventional master planning approach.

Kazerun located in the Fars province is one of the somehow medium-sized cities in the Iran's urban system which experienced a rapid rate of physical growth in recent decade. Due to the unorganized expansion of the city, the spatial organization of the city and its main structure is changed to an irregular form in which urban facilities and services are being scattered in different parts of the city.

Analyzing urban sprawl, its causes and impacts in Kazerun with regard to the role of masterplan is the objective of this paper. In this way, discovering the rate of urban sprawl, its causes and impacts are targeted. Also, the role of the masterplan in urban sprawl will be discussed. Although several studies have been undertaken on the sprawl and zoning philosophy and practice in western societies, the impacts of the masterplanning on sprawl considering the specific conditions of developing nations have remained largely unknown. This paper investigates the sprawl phenomena and its main causes in Kazeroun, a mid-sized city in the southwest of Iran. The contribution of this study is that it examines the sprawl and the role of masterplanning in a different context (a developing country) with different socio-economic and spatial characteristics where such academic research is lacking. The findings of the research will be helpful in proposing a set of policies for a balanced urban development.

\section{Materials and Methods}

Kazerun as the case of this study, has an area over 2' 570 hectare located 145 kilometers away from the west of Shiraz and 1'060 kilometers from the capital city of Tehran, in the Middle-West of Fars province (Fig. 1). Currently, Kazerun is composed of four regions and 25 neighborhoods (Naghsh-Mohit Consultant, 2004).

Kazerun has two master plans adopted and the latest one, approved in 1991 is taken in consideration in this study. This study can be considered as a functional evaluation study which describes urban sprawl, its causes and its effects in Kazerun with a consideration on the role of master plan in the physical development. The data collected from secondary sources including the maps and documents related to the study area from 1956 to 2011 . 


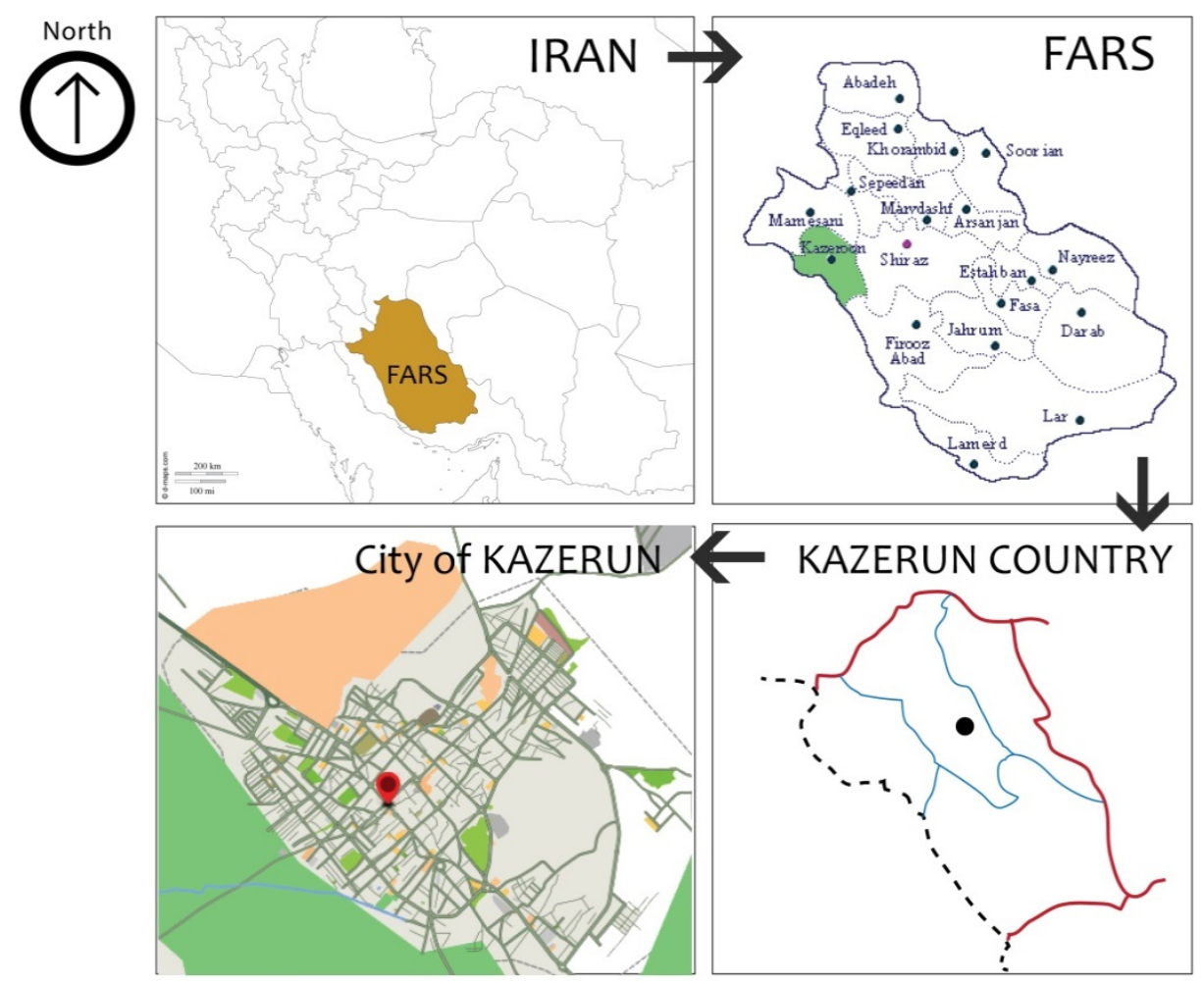

Figure 1 . The case study area

\section{Results}

\subsection{The Spatial Structure of the City}

The present physical form of Kazerun is like a circle with some erratic divisions inside the central and peripheral parts and squared divisions in the peripheral newly constructed parts, which gradually and by time and by the expansion of the city in north west and the entrance of the city, is about to transform into a scattered linear pattern. Also, Kazerun has a grid road network system. The periodic development of Kazerun during the past 40 years shows that the city experienced slight growth until 1980. Then, due to the increasing interactions with two major metropolitans, Shiraz and Bushehr, and peripheral areas, the growth pattern changed to linear and scattered forms. This leads to an elongated shape from the northeast to the northwest just like two long arms and partly expansion to the southeast, so that by the continuation of this situation, the southeast parts of the city will also experience such a linear growth.

According to Table 2, the annual rate of population growth in Kazerun between 1956 and 2011 was 1.92 percent, in average. It is observed that the growth rate of Kazerun was small. A gradual increase in population growth can be observed from 1956 to 1986. On the other hand, the population growth rate had decreased between 1996 and 2011 with some fluctuations. Comparing the rate of Kazerun population growth with the average annual rate of country population growth confirms this. Hence, it is observed that within all the studied periods in the past forty years, with regard to the changes in the population growth, Kazerun was too far from the average urban growth of the whole country. Despite the slow and gradual growth, the Kazerun has had a sporadic horizontal expansion and in what follows, we measure its size base on the population and the area of build environment in the city. 

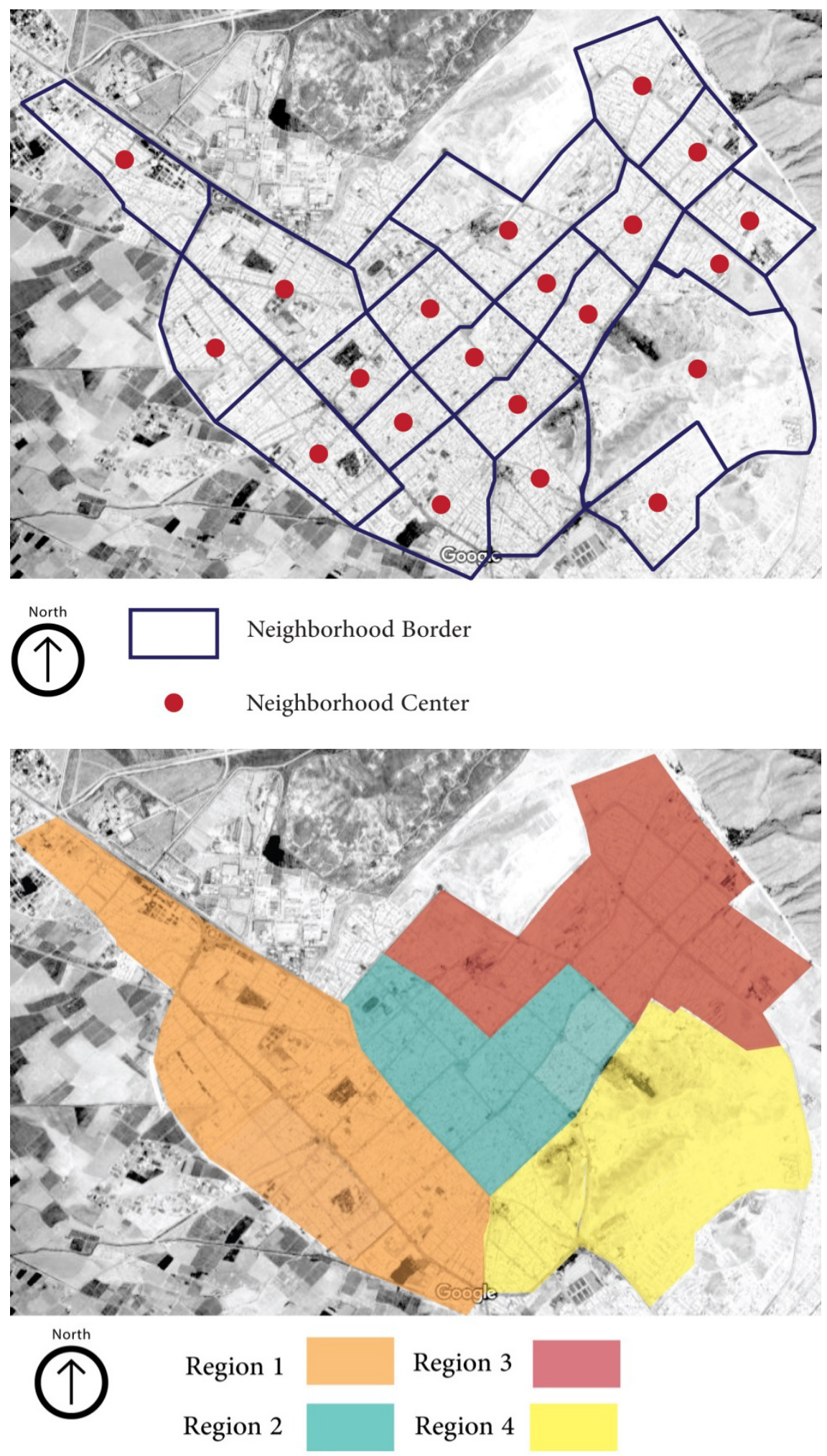

Figure 2. Divisions of Kazerun 
Table 1. Kazerun population's growth comparing to the country

\begin{tabular}{llllll}
\hline year & Kazerun & \multicolumn{3}{l}{ Iran } \\
\cline { 2 - 6 } & Population & $\begin{array}{l}\text { Population } \\
\text { growth rate }\end{array}$ & $\begin{array}{l}\text { Urban } \\
\text { population }\end{array}$ & $\begin{array}{l}\text { Urban } \\
\text { growth rate }\end{array}$ & population \\
\hline 1956 & 30641 & - & 6002621 & - & \\
1966 & 39758 & 2.6 & 9795810 & 4.9 & \\
1976 & 51527 & 2.7 & 15854680 & 4.8 & \\
1986 & 73444 & 3.6 & 26844561 & 5.4 & \\
1996 & 81713 & 1.1 & 36817789 & 3.17 & \\
2006 & 84594 & 0.35 & 48259964 & 2.74 & \\
2011 & 89685 & 1.18 & 53646661 & 2.14 & \\
Average & 64480.25 & 1.92 & 28174583.7 & 3.85 & \\
\hline
\end{tabular}

\subsection{The Rate of Sprawl by Holdern Index}

Several metrics are suggested to measure the composition and configuration of urban growth pattern which generally show how urban areas developed over time. In this study, the Holdern index is used to calculate the rate of sprawl for the period of 1976 to 2011 using the following formula (Beck, 2003):

$$
\operatorname{Ln}\left(\frac{\mathrm{P}_{1}}{\mathrm{P}_{0}}\right)+\operatorname{Ln}\left(\frac{\mathrm{B}_{1}}{\mathrm{~B}_{0}}\right)=\operatorname{Ln}\left(\frac{\mathrm{A}_{1}}{\mathrm{~A}_{0}}\right)
$$

$\mathrm{P}_{1}=$ population at the end of the period

$\mathrm{P}_{0}=$ population at the beginning of the period

$B_{1}=$ Gross per capita at the end of the period

$\mathrm{B}_{0}=$ Gross per capita at the beginning of the period

$A_{1}=$ area of the city at the end of the period

$A_{0}=$ area of the city at the of the period

The variables of this model for Kazerun during the years 1976 to 2011 are as follow:

$$
\begin{aligned}
& P_{1} \text { (Year 1976): } 51527 \text { persons } \\
& P_{0} \text { (Year 2011): } 89685 \text { persons } \\
& B_{1} \text { (Year 1976): } 29.11 \mathrm{~m}^{2} \\
& B_{0} \text { (Year 2011): } 286.55 \mathrm{~m}^{2} \\
& A_{1} \text { (Year 1976): } 150 \text { Hectares } \\
& A_{0} \text { (Year 2011): } 2570 \text { Hectares }
\end{aligned}
$$

By putting these numbers in Holdern formula, the result will be:

$$
\begin{aligned}
& \operatorname{Ln}\left(\frac{89685}{51527}\right)+\operatorname{Ln}\left(\frac{286.55}{29.11}\right)=\operatorname{Ln}\left(\frac{2570}{150}\right) \\
& \operatorname{Ln}(1.74)+\operatorname{Ln}(9.84)=\operatorname{Ln}(17.13) \\
& (0.5538)+(2.2864)=2.8408
\end{aligned}
$$

Then, by dividing each side of the equation to 2.8408 , the percentage of the distribution of population growth and annual gross urban land growth will be obtained.

$$
\left(\frac{0.5538}{2.8408}\right)+\left(\frac{2.2864}{2.8408}\right)=\left(\frac{2.8408}{2.8408}\right)
$$

If the year 1976 is considered as the starting point and the year 2011 as the end point of this period, from the total physical growth or the increase in the city area in this period, 19 percent corresponded to the natural growth 
of the population and immigration and the other 81 percent associated with the horizontal dispersion or expansion.

During the recent 35 years, due to Holdern equation, approximately 80 percent of the physical growth of the city occurred due to some factors apart from the factor of population which shows the problem of very high dispersion in Kazerun development. The result of this situation had been resulted in a reduction in the gross density and an increase in the gross per capita of urban land, which are too high. So that during these 35 years, gross per capita of urban land has increased From 29.11 square meters to 286.55 square meters. Since, this increase has been made in the form of wastelands, so now is not useful for citizens.

\subsection{The Rate of Sprawl by Shannon Index}

Also, for the assessment of sprawl in Kazerun, the Shannon entropy index is used. This measure can calculate the rate of sprawl in the city and the suburban areas. The basic logic of computation in this index is to compare the built area in the neighborhoods or districts with the total built area in the neighborhoods or districts according to the following formula (Shannon, 1948):

$$
H=-\sum_{i=1}^{n} P_{i} \times \operatorname{Ln}\left(p_{i}\right)
$$

In this formula, $\mathrm{Pi}$ is the ratio of built area (total residential density) of the region $\mathrm{i}$ to the total built over all areas and $\mathrm{n}$ refers to the total number of areas. In order to interpret the output of this measure, the final value obtained from the index is compared with the value of $\operatorname{Ln}(\mathrm{n})$ and the closer the value of entropy to the value of $\operatorname{Ln}(\mathrm{n})$, the more sporadic it is.

In this part, the entropy calculation for Kazerun city is done for the whole city with the consideration of its four regions. The data of population and area of the city is used by separating the region in the period of 2004. The result is shown in the following table.

Table 3. Entropy value calculation for the sprawl

\begin{tabular}{|l|l|l|l|l|}
\hline Region & Area $(\mathrm{H})$ & \multicolumn{1}{|c|}{$p_{i}$} & \multicolumn{1}{|c|}{$\operatorname{Ln}\left(p_{i}\right)$} & $p_{i} \times \operatorname{Ln}\left(p_{i}\right)$ \\
\hline 1 & 601.43 & 0.3020 & -1.1973 & -0.3615 \\
\hline 2 & 359.14 & 0.1804 & -1.7125 & -0.3089 \\
\hline 3 & 429.77 & 0.2159 & -1.5329 & -0.3309 \\
\hline 4 & 600.57 & 0.3016 & -1.1986 & -0.3614 \\
\hline Total & 1990.91 & $\sum p_{i}=1$ & $p_{i} \times \operatorname{Ln}\left(p_{i}\right)=1$ & -1.3627 \\
\hline
\end{tabular}

$\operatorname{Ln}(4)=1.3862$

According to the table, the value of entropy (1.363) is close to the final limit of the classes (1.386), hence showing the high level of sprawl happened in Kazerun. It is worth mentioning that in comparing the value of entropy and final limit, always the absolute value of entropy is considered, this fact is eliminated from the value.

\subsection{The Sprawl Impacts}

The impacts of scattered urban growth can be studied in environmental, social, economic and physical aspects (Zhang et al., 2007; Travisi et al., 2010; Hasse and Richard, 2003; Nuissl et al., 2009). The qualitative expert survey questionnaire is used as a tool to verify the most important consequences of sprawl in Kazerun. First, the most important negative effect of sprawling was extracted from the literature. Then 30 experts worked as managers and officials in Kazerun Municipality, the Department of Urban Development, the Water and Sewage Organization and the Department of Transportation who are fairly familiar with the local area, were asked to evaluate each of the potential effects with a Likert system of five point scale from one (the least importance) to 5 (the most importance). The Freedman non-parametric test was used to compare the means and rank (Table 4): 
Table 4. The scoring of the effects of scattered expansion from the experts' viewpoint

\begin{tabular}{|c|c|c|c|c|}
\hline Dimension & Factor & Mean & Mean Rank & Rank \\
\hline Physical & Fragmentation of urban form & 3.95 & 7.30 & 1 \\
\hline Economical & Increasing the cost of infrastructures and utilities & 3.74 & 7.23 & 2 \\
\hline Environmental & Changing the land use from farm into built up area & 3.71 & 7.13 & 3 \\
\hline Environmental & Destruction of natural landscape & 3.69 & 6.78 & 4 \\
\hline Environmental & Reducing the area of the territory farmland & 3.68 & 6.55 & 5 \\
\hline Physical & Decreasing accessibility to services and facilities & 3.41 & 6.42 & 6 \\
\hline Physical & Reducing the quality of streetscapes & 3.38 & 6.37 & 7 \\
\hline Environmental & Dropping the quality and quantity of water resources & 3.21 & 6.23 & 8 \\
\hline Economical & Increasing car dependency for transport & 2.96 & 6.22 & 9 \\
\hline Social & Reducing the social capital & 2.53 & 6.20 & 10 \\
\hline Environmental & Air pollution & 2.20 & 6.08 & 11 \\
\hline Social & Increasing the rate of crime & 2.02 & 5.48 & 12 \\
\hline $\mathrm{n}=30$ & Chi-square $=10.706$ & & & \\
\hline
\end{tabular}

The highest effect of scattered expansion of Kazerun is physical, stated as the fragmentation of urban form (mean rank $=7.30$ ). On the other hand, the least effect of this phenomenon with an average score of 5.48 was increasing the rate of crime.

Overall, these results show that in the environmental part, changing the land use from farm into built up area, destruction of natural landscape, reducing the area of the territory farmland, dropping the quality and quantity of water resources, and air pollution in social part, reducing the social capital and also increasing the rate of crime, in the economic sector, increasing the cost of infrastructures and utilities, increasing car dependency for transport can be mentioned. However, the most important part of these inflicted effects from sprawling relates to its physical dimension which includes the fragmentation of urban form, increasing car dependency for transport, decreasing accessibility to services and facilities, destruction of natural view and urban landscape and the change of land use from farm into built up area.

\subsection{The Role of Urban Master Plan in Sprawling}

The provided masterplans for Kazerun city, was an effort to reorganize the city by local partitioning, offering the new physical divisions and the optimized distribution of services, amenities and urban facilities. However, one of the biggest problems and weaknesses confronting the city expansion of Kazerun is the lack of control in city expansion in line with the offered proposals in the masterplan.

The physical expansion of Kazerun during the past two decades mostly occurred in the northwest parts of the city known as 65 hectare land, which is out of the boundary and the physical border of the city. The fourth region, located at the east and south-east of Kazerun in the masterplan has been considered as the first priority for the future development of city in 1991. So that in some neighborhoods in these four regions, including the neighborhoods number four, with the predicted capacity of 3'270 people, few populations has resided.

The masterplan was not successful in predicting future population. The study of provided masterplans in Iran during the past two decades shows that population estimations in most cases have not realized due to different reasons. However, its consequence was the addition of much land into the legal limit of the cities in order to accommodate future population. This also happened to Kazerun and the predicted population for the year 2000, was $124^{\prime} 000$ persons which did not appear in reality.

While the proposed growth area suggested by the masterplan of Kazerun located in the east part of Kazerun, the developer companies started constructing in the west and northwest parts. According to the experts' narrative report, the most important reasons for violation of the masterplan and sprawling in Kazerun were:

- $\quad$ Lack of a clear policy on urban growth boundary (UGB),

- Inability of poor immigrants to find affordable housing inside the defined urban area,

- Land market inflation and lack of governmental land banking for public uses, 
- Establishment of some urban facilities and large-scale projects outside of the city borders,

- Uncontrolled activities of developers and housing cooperative companies,

- Passiveness of the municipality with regard to public nuisances on properties located on fringe,

- Inability of the local government to control the usage of vacant lands by private owners,

- Driving forces arisen from the road network development towards nearby settlements.

\section{Conclusion and Policy Implication}

This paper studied the urban growth pattern of Kazerun, a medium-sized city in south of Iran. Using population and area data available from secondary formal sources, the growth pattern was compared to national statistics. Furthermore, two well-known landscape metrics included Holdern and Shannon indices were applied to measure the extent of urban sprawl. As part of research methodology, 30 planning and engineering experts working in governmental agencies were asked to explain the causes and effects of urban sprawl in Kazerun. The results confirmed that several factors affected the urban development pattern. Moreover, a number of physical, environmental, economic and social impacts were discovered as the consequence of current fragmented growth pattern. This study showed that in many cases the sprawling areas are the outcome of insufficient control on land use planning. Such fragmented constructions cannot be termed planned development because no target is observed behind the growth pattern of them (Masoumi, 2012). Good samples of such developments are the unplanned constructions along the arterial roads oriented to Shiraz and Bushehr as two important neighboring cities. Such growths were not been predicted by the master plans so they have nothing in common with planned development but they are just the outcome of fast urbanization and lack of strict control by planning authorities.

In order to provide a policy packages for balanced development of Kazerun, the further recognition of sprawling causes is required. At first glance, converting the growth pattern from horizontal low-density development to medium-density infill development is a possible solution. The alternative growth pattern should be shaped on the abandoned and unused lands inside the current limits of the urban area. The development on those lands which had been far from the attention during the continuous expansion of the city has a priority. Establishing a vibrant urban core through revising existing land-use codes and regulations and continuing investments on central area to improve the quality of place is the second recommendation.

The results would be beneficial to help urban planners/managers in their role of evaluating the value of development proposals by identifying how the undesirable consequences of sprawl can be included in their evaluation. Building new homes on brownfield sites and extending the usage of older infrastructure while balancing competing land use interests is another successful strategy practiced in European cities to overcome sprawl and can be replicated for the case study area. The local government should work to keep sufficient affordable, attractive, and updated housing choices within the current urban border and the developed area in order to accommodate low-income families and new migrants. Enhancing the quality of public spaces and improving transportation systems other than private vehicle such as public transport, walking and cycling is recommended to decrease the level of car dependency.

A useful direction for future research is to compare the calculation and qualitative analysis of this study with other med-sized cities in Iran. Furthermore, examining the reliability of quantitative analysis and the accountability of the used methods in specific circumstances such as in Iran would be interesting.

\section{Acknowledgement}

The authors would like to thank two anonymous referees for their constructive comments, and also our colleagues, Peyman Najafi and Sajad Askari from Urbanism Department, Shiraz University for their kind help on mapwork.

\section{References}

Ahmadi,V., Chi-Ani, V. A. I., Farkisch, H., \& Surat, M. (2012). Morphological study of urban hierarchy in Boshrooyeh city of Iran. Archnet-IJAR, 6(3), 56-71.

Anderson, R., \& Samartin, A. (1983). A model for the economic evaluation of master city plans: a pilot study of Vtisteras, Sweden. Applied Mathematical Modeling, 7(5), 345-355. https://doi.org/10.1016/0307-904X(83)90133-6

Beck, R. (2003). Out-smarting Smart Growth: Population growth, Immigration, and the Problem of Sprawl. Washington, D. C.: Center for Immigration Studies.

Burchell, R. W., \& Shad, N. A. (1999). The evolution of the sprawl debate in the United States. West Northwest, 
5(2), 137-160.

Capello, R., \& Camagni, R. (2000). Beyond Optimal City Size: An Evaluation of Alternative Urban Growth Patterns. Urban Studies, 37, 1479-1496. https://doi.org/10.1080/00420980020080221

Catal'an, B., Saur'I, D., \& Serra, P. (2008). Urban sprawl in the Mediterranean Patterns of growth and change in the Barcelona Metropolitan Region 1993-2000. Landscape and Urban Planning, 85, 174-184.

City-Parish Planning Commission. (2004). Information Bulletin Number 43. Retrieved from http://www.in.gov/dor/3650.htm

Cowan, R. (2005). The Dictionary of Urbanism. Streetwise Press, and Wiltshire.

Davis, C., \& Schaub, T. (2005). A trans-boundary study of urban sprawl in the Pacific coast region of North America: The benefits of multiple measurement methods. International Journal of Applied Earth Observation and Geo-information, 7, 268-283. https://doi.org/10.1016/j.jag.2005.06.007

Downs, A. (1998). How America's cities are growing: the big picture. Brookings Review, 16(4), 8-12. https://doi.org/10.2307/20080808

Ewing, R. (1997). Is Los Angeles-style sprawl desirable?. Journal of the American Planning Association, 63(1), 107-126. https://doi.org/10.1080/01944369708975728

Han, H., Lai, S., Dang, A., Tan, Z., \& Wu, C. (2009). Effectiveness of urban construction boundaries in Beijing: An assessment. Journal of Zhejiang University Science A, 10, 1285-1295. https://doi.org/10.1631/jzus.A0920317

Hasse, J. E., \& Lathrop, R. G. (2003). Land resource impact indicators of urban sprawl. Applied Geography, 23, 159-175. https://doi.org/10.1016/j.apgeog.2003.08.002

Iran Statistics Bureau (ISB). (2011). Results of general census of population and housing in 1956-2011. Retrieved from http://www.amar.org.ir/default.aspx?tabid=1828, (In Persian)

Karimi, K. (2002). Iranian organic cities demystified: a unique urban experience or an organic city like others. Built Environment, 28(3), 187-201

Kim, S., \& Rowe, P. G. (2013). Are master plans effective in limiting development in China's disaster-prone areas? Landscape and Urban Planning, 111, 79-90. https://doi.org/10.1016/j.landurbplan.2012.12.001

Madanipour, A. (2006). Urban planning and development in Tehran. Cities, 23(6), 433-438. https://doi.org/10.1016/j.cities.2006.08.002

Madanipour, A. (2010). The limits of scientific planning: Doxiadis and the Tehran Action Plan. Planning Perspectives, 25(4), 485-504. http://dx.doi.org/10.1080/02665433.2010.505066

Masoumi, H. E. (2012). Urban sprawl in Iranian cities and its differences with the western sprawl. SPATIUM International Review, 27, 12-18. https://doi.org/10.2298/SPAT1227012E

Mohammadi, H. (2010). Citizen Participation in Urban Planning and Management, a Case Study of Saadi Community. Kassel: Kassel University.

Municipal Research and Services Center of Washington. (1997). Infill Development Strategies for Shaping Livable Neighborhoods. $\quad$ Report $\quad$ No.38. $\quad$ Retrieved from http://www.landscapes2.org/ToolsLandscape/Pages/InFill.cfm

Naghsh Moheet Consultants. (2004). Kazerun Action Plan. Department of Roads and Urbanism, Fars, Iran.

Ngoran, D. S., \& Xu, X. (2015). Addressing urban sprawl in Douala, Cameroon: Lessons from Xiamen integrated coastal management. Journal of Urban Management, 4(1), 53-72. https://doi.org/10.1016/j.jum.2015.05.001

Nuissl, H., Haaseb, D., Lanzendorfc, M., \& Wittmerd, H. (2009). Environmental impact assessment of urban land use transitions- A context-sensitive approach.

PanahandehKhah, M., Farhoodi, R., Gharakhlou, M., \& Ghadami, M. (2009). A critique of the prevailing comprehensive urban planning paradigm in Iran: the strategic planning approach. Planning Theory, 8(4), 335-361. https://doi.org/10.1177/1473095209341328

Pars Arayeh Consultants. (2009). Site selection studies for choosing suitable places for "Mehr Complex housing" projects.

Pendse, S. H. (1991). Perspective on an Economic Future. Green wood press published, G.B. 
Rasoolimanesh, S., Jaafar, M., \& Badarulzaman, N. (2013). Urban planning and management system in Iran: a review and assessment. Middle-East Journal of Scientific Research, 18(2), 220-229.

Shannon, C. (1948). A mathematical theory of communication. Bell System Tech. J., 27, 379-423. https://doi.org/10.1002/j.1538-7305.1948.tb01338.x

Sharifi, A., Chibab, Y., Okamotoc, K., Yokoyamac, S., \& Akito, M. (2014). Can masterplanning control and regulate urban growth in Vientiane, Laos? Landscape and Urban Planning, 131, 1-13. https://doi.org/10.1016/j.landurbplan.2014.07.014

Squires, G. D. (2002). Urban Sprawl: Causes, Consequences, and Policy Responses (2nd ed.). the urban institute press, Washington D.C.

Tian, L., \& Shen, T. (2011). Evaluation of plan implementation in the transitional China: A case of Guangzhou city master plan. Cities, $28,11-27$. https://doi.org/10.1016/j.cities.2010.07.002

Travisi, C., Camagni, R., \& Nijkamp, P. (2010). Impacts of urban sprawl and commuting: a modelling study for Italy. Journal of Transport Geography, 18, 382-392. https://doi.org/10.1016/j.jtrangeo.2009.08.008

Yuea, W., Liuc, Y., \& Peilei, F. (2013). Measuring urban sprawl and its drivers in large Chinese cities: The case of Hangzhou. Land Use Policy, 31, 358-370. https://doi.org/10.1016/j.landusepol.2012.07.018

Zeng, C., Liub, Y., Steind, A., \& Limin, J. (2015). Characterization and spatial modeling of urban sprawl in the Wuhan Metropolitan Area, China. International Journal of Applied Earth Observation and Geo information, 34, 10-24. https://doi.org/10.1016/j.jag.2014.06.012

Zhang, X., Chen, J., Manzhi, T., \& Yanci, S. (2007). Assessing the impact of urban sprawl on soil resources of Nanjing city using satellite images and digital soil databases. Catena, 69, 16-30. https://doi.org/10.1016/j.catena.2006.04.020

\section{Copyrights}

Copyright for this article is retained by the author(s), with first publication rights granted to the journal.

This is an open-access article distributed under the terms and conditions of the Creative Commons Attribution license (http://creativecommons.org/licenses/by/4.0/). 